\title{
A Conceptual Culture Model for Design Science Research
}

\author{
Thomas Richter ${ }^{1}$
}

\begin{abstract}
The aim of design science research (DSR) in information systems is the user-centred creation of ITartifacts with regard to specific social environments. For culture research in the field, which is necessary for a proper localization of IT-artifacts, models and research approaches from social sciences usually are adopted. Descriptive dimension-based culture models most commonly are applied for this purpose, which assume culture being a national phenomenon and tend to reduce it to basic values. Such models are useful for investigations in behavioural culture research because it aims to isolate, describe and explain culture-specific attitudes and characteristics within a selected society. In contrast, with the necessity to deduce concrete decisions for artifact-design, research results from DSR need to go beyond this aim. As hypothesis, this contribution generally questions the applicability of such generic culture dimensions' models for DSR and focuses on their theoretical foundation, which goes back to Hofstede's conceptual Onion Model of Culture. The herein applied literature-based analysis confirms the hypothesis. Consequently, an alternative conceptual culture model is being introduced and discussed as theoretical foundation for culture research in DSR.
\end{abstract}

Keywords: Culture, conceptual culture model, design science research.

JEL Codes: F20, M10, M14, M15, Z10.

Available Online: 28-03-2016.

This is an open access article under Creative Commons Attribution 4.0 License, 2016.

\section{$1.0 \quad$ INTRODUCTION}

For some decades, globalization and competition on the international market have consistent themes in the context of Information Systems (IS) literature. As one paradigm in the field, Gregor and Hevner (2013: 337) assign design science research (DSR) to 'the construction of a wide range of socio-technical artifacts such as decision support systems, modelling tools, governance strategies, methods for IS evaluation, and IS change interventions'. Baskerville (2008: 441) understands DSR as having 'to do with the systematic creation of knowledge about, and with, design'. He emphasizes that DSR neither is an IT artifact in itself, nor a methodology, or a separate academic discipline. Much more, 'design is problem-driven, and leads to an artifact that solves the problem when the artifact is introduced into nature'. However, he keeps the question open weather artifacts exclusively are written code or also concepts leading to written code (idem: 442). Nunamaker \& Briggs (2012) suggest not to exclusively focus DSR on IT-artifacts but to additionally

1TELIT@University of Duisburg-Essen, E-mail: thomas.richter@uni-due.de 
consider any kind of systems in organizations. Frank, Schauer \& Wigand (2008) and Drechsler (2013) emphasize to consider both the organizational and social aspects of socio-technical systems. For this contribution, the latter perspective of DSR is adopted and culture as a general concept is understood as 'the customs, beliefs, social structure, and activities of any group of people who share a common identification and who would label themselves as members of that group' (Oetting 1993: 41). According to Norman (1988: 189-201), the needs and desires of the intended users need to be fully understood in order to apply a usercentred design, which is a basic requirement for the later acceptance of the product. Following Ehn \& Löfgren (2009), applied culture-related investigations usually focus on imminent problems, such as the contextualization of product and artifact design (Lai \& Wong, 2003; Hevner et al., 2004), the development of international marketing strategies, or human resource and management issues. In order to successfully design IT-artifacts at international level, developers and enterprises are required to adapt their products and strategies to foreign and often unknown contexts (Goeltz, 2014). Thus, understanding both, the particular perceptions and attitudes of the target group and to which extent these differ from one's own is essential (Ehn \& Löfgren 2009: 41) in order to drive user-centred design decisions.

For the comparative investigation of culture across societies, the work of Hofstede (1980) was groundbreaking for its time (Westwood \& Everett, 1987), and within the last three decades, it achieved a central role for culture-related investigations in the field (Leidner \& Kayworth, 2006; Jones, 2007; Ali, Tretiakov, \& Crump, 2009). With his Culture Dimensions Model, Hofstede classified national culture through four value-based dimensions and developed related score values for a large number of countries (Hofstede 1980). Subsequently, two further dimensions were added to this model (Hofstede \& Bond, 1988; Hofstede, Hofstede, \& Minkov, 2010). According to Köppel (2002), one central reason why Hofstede's approach to describe and compare cultures across countries has reached such a high level of prominence amongst other approaches is to be found in its very simple design. Alongside its achieved prominence, Hofstede's Culture Dimensions Model and particularly the predefined score values have constantly been challenged and criticized (Kogut \& Singh, 1988; McSweeney, 2002; Leidner \& Kayworth, 2006; Jones, 2007; Ng, Lee, \& Soutar, 2006; Tsui, Nifadkar, \& Olu, 2007; Ailon, 2008; Tarras \& Steel, 2009; Douglas \& Liu, 2011). Apart of methodological and ethical issues, particularly the assignment and the deduction of concrete perceptions and attitudes in very specific contexts to/from such a small set of value-based dimensions have been questioned.

For the following, two generally different types of culture models are distinguished, which are descriptive and conceptual culture models. The purpose of descriptive culture models, such as the models from Hofstede (1980; 1997/2010), Koester and Olebe (1988), Hall \& Hall (1990), House et al. (1993, 2004), Trompenaars \& Hampden Turner (1997), Schwartz (1999), Adler (2002), and Inglehart \& Wetzel (2010), is either to provide a framework for the classification of chosen culture-specific aspects within a single society or the comparison of selected culture-specific characteristics across different societies; mostly on the basis of dimensions. The trend to quantifying national culture alongside a small number of selected attributes started in the 1950 s (e.g., Kuhn \& McPartland, 1954; Haire, Ghiselli, \& Porter 1966). Value-based dimension models had their breakthrough in the 1980 s after Hofstede had completed his large-scale employee-related survey at IBM. The results of this survey led to the design of Hofstede's Culture Dimensions Model. In contrast to descriptive culture models, conceptual culture models aim to describe and explain aspects of culture itself. Examples for conceptual culture models are Osgood's Percepta and Concepta (1951: 209-213), Hofstede et al's Onion Model of Culture (1990: 291, 1997/2010: 11), Schein's Iceberg Model (1985, 2010), Derr \& Laurent's triangle of culture (1989: 465), Scholz' culture model on influencing levels of societies (2000: 239), and Leidner \& Kayworth's model of culture-specific conflict potentials (2006: 374). Three generally different dimensions of culture were found to being focused by conceptual culture models, i. e. society-specific contexts and related cultural interdependencies (Derr \& Laurent, 1989; Scholz, 2000; Straub et al., 2002; Karahanna, Evaristo, \& Srite, 2006; Leidner \& Kayworth, 2006), the visibility of cultural phenomena (Osgood, 1951; Ruch and Zimbardo, 1974; Schein, 1985), and the persistence/imprinting-depth of cultural phenomena (Gagliardi, 1986; Hofstede et al., 1990; Hofstede, 1997/2010). Conceptual culture models can constitute the theoretical foundation of descriptive culture models. 
The concept underlying dimensional culture models is very pragmatic, and the achievable level of rigour appears to be acceptable just because of limited research time (Ehn \& Löfgren 2009). Authors in the fields increasingly urge a more detailed view on cultural phenomena, the implementation and development of alternative research approaches, and more precise methods for culture-related research (e.g. Kirkman, Lowe, \& Gibson, 2006; Leidner \& Kayworth, 2006; Smith, 2006; Tsui, Nifadkar, \& Olu, 2007; Gelfand, Nishii, \& Raver, 2007; Leung \& Ang, 2009; Tarras, Rowney, \& Steel, 2009). In this context, alternatives have been suggested to substitute the rather traditional "western" understanding (Müller, 1996: 84) of culture as a set of characteristics, which describe attitudes and perceptions of a majority of people within a group. Pelto (1968) recommends a configuration of diversity by considering how tightly or loosely a society adheres to its implicit rules (also Gelfand, Erez, \& Aycan, 2007). Pless and Maak (2004) suggest an understanding of culture as the level to which a society accepts deviations from the norm. Bruk-Lee et al. (2009) and Leach-López and Jack (2014) emphasize the link between individual perceptions and culture-related phenomena. Understanding culture in terms of the philosophy of Yin and Yang, Fang (2011: 31) advises against limiting investigations to dimensional values but rather consider related paradoxical values.

The criticism against the use of Hofstede's Culture Dimensions Model did neither lead to substantial changes in the research practice in IS, nor did it intensify the discussion regarding its general applicability in the field (Leidner \& Kayworth, 2006; Ali et al. 2009). In their literature analysis, Ali et al. (2009: 254) found three reasons for this model's adaptation, which were its simplicity, its supposed applicability to different contexts, and its acceptance within the community. It seems that inspiring more case-sensitive investigations requires not just critique, but a basic shift in the understanding of aspects of culture, which are relevant to drive detailed enough design-oriented decisions. Different to Hofstede's Culture Dimensions Model, his conceptual Onion Model of Culture (1997/2010: 11) has rarely been challenged, even though it substantiates the most frequently criticized assumptions of the Culture Dimensions Model. Hofstede claims that the set of phenomenon types considered within the Onion Model of Culture cover the total concept of culture 'rather neatly' (idem 2010: 7).

As working hypothesis, it is assumed that the support, Hofstede's Onion Model of Culture provides as conceptual framework for DSR, is insufficient. Hofstede's Onion Model of Culture has been selected for the following critical analysis because of its prominence amongst all other conceptual models, because it strongly supports focusing on cultural values and thus, encourages the application of value-based culture dimensions models, and particularly, because of the considered cultural characteristics, which are the different types of cultural phenomena and their persistence over time. These characteristics have a high level of relevance for culture-related investigations in DSR.

For this contribution, Hofstede's has systematically been analysed, mainly on the basis of a literature review across 65 years of culture anthropology and beyond. The Onion Model of Culture is being challenged for its currency, completeness and usefulness, particularly but not exclusively for the context of DSR. As central outcome, the working hypothesis eventually proved true. Culture, as a construction, is being remodelled in terms of DSR. Subsequently, the construction is being transferred into an improved conceptual culture model. This model provides an alternative theoretical foundation for culture-related research in DSR and shall serve as an entry-point for further discussion.

\subsection{HOFSTEDE'S ONION MODEL OF CULTURE: INTRODUCTION}

With the Onion Model of Culture, Hofstede et al. (1990) illustrated the level of depth in which cultural phenomena are rooted in people's minds. The level of depth further indicates the persistence of cultural phenomenon types: The less deeply rooted a cultural phenomenon is, the more likely it is to be changed or discarded. This assumption is represented through the onion peeling analogy.

The model, reproduced in Figure 1, differentiates between four types of cultural phenomena, i.e. from inside to outside, "Values", "Rituals", "Heroes", and "Symbols". Hofstede et al. (2010: 8-9) define "Values" as "broad tendencies to prefer certain states of affairs over others. Values are feelings with an added 
arrow indicating a plus and a minus side. They deal with pairings such as the following: evil vs. good, dirty vs. clean, $[$....'.

Figure 1: Hofstede's onion model of culture (Hofstede et al., 1990: 291)

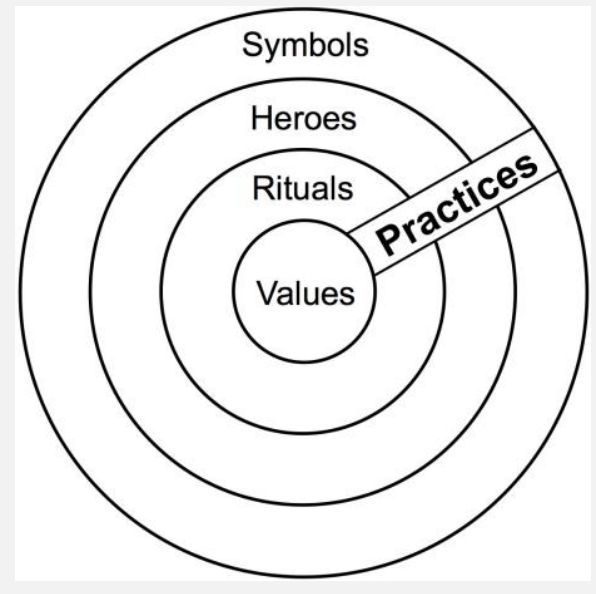

"Rituals" are defined as "collective activities that are technically superfluous to reach desired ends but that within a culture, are considered socially essential. They are therefore carried out for their own sake. Examples are ways of greeting and paying respect to others, as well as social and religious ceremonies'.

"Heroes" are 'persons, alive or dead, real or imaginary, who possess characteristics which are highly prized in a culture, and who thus serve as models for behaviour'; provided examples are Barbie, Batman, Snoopy, Asterix, and others.

"Symbols" are defined as 'words, gestures, pictures or objects that carry a particular meaning that is recognized as such only by those who share the culture. The words in a language and jargon belong to this category, as do dress, hairstyles, flags and status symbols. New symbols are easily developed and old ones disappear'.

Through the label "Practices", Hofstede's Onion Model of Culture additionally proposes that "Values" exclusively are learned within early childhood and persist in a person's mind for a lifetime, as a "mental programming". In contrast, "Rituals", "Heroes", and "Symbols" are learned during one's lifetime and change with new practices on the individual level (Hofstede et al., 2010: 10-11).

\subsection{HOFSTEDE'S ONION MODEL OF CULTURE: CRITICAL DISCUSSION}

In the following, first, the definitions of each cultural phenomenon type are contrasted against the common understanding within the culture-researching core disciplines and beyond, and particularly, the claim for completeness is questioned. Subsequently, the level of distinction of the chosen types of cultural phenomena is challenged according to their persistence over time. Afterwards, Hofstede's statement regarding the origin of cultural biasing briefly is discussed. Finally, the proportionality of the onion and the onion peeling metaphors are focused.

\subsection{CULTURAL PHENOMENON TYPES: TERM DEFINITIONS AND COMPLETENESS}

Hofstede et al. (2010: 8) understand "Values" as "broad tendencies to prefer certain states of affairs over others'. Such "Values" are 'feelings', which are perceived as dialectical phenomena between two extreme poles (e.g. good vs. evil, dangerous vs. save, ugly vs. beautiful).

Schwartz (1994: 88), in contrast, assigns basic values to 'desirable goals varying in importance that serve as guiding principles in people's lives'. Summing up several definitions, basic values are characteristics for human behaviour that, in implicit agreement of the society, are relevant to be met in order to maintain 
the society (e.g. Kluckhohn, 1953; Rokeach, 1973). Such implicit agreements often are substantiated through written laws (Mauss, 1990: 120-156; Oeser, 1990: 45). While basic values generally are unchallenged regarding their relevance for culture-related investigations, the appropriateness of limiting characterizations of whole societies to this level is questionable. Morris (1956: 11) expresses that the reason for particular attitudes and behaviour can hardly be assigned to a single isolated value. Morris further advances the view that the relevance of basic values must be evaluated on the individual level because the 'nurse and the soldier in a culture cannot show the same operative values in their actions' (Morris, 1956: 198). Tajfel and Turner (1986: 11) argue that classifying cultures on the basis of isolated attributes generally is not useful because conflict situations usually arise through constellations of particularly weighted attributes. For Tarras and Steel (2009: 2), focusing research on basic values leads to ignorance regarding other relevant cultural phenomena. Church and Katigbak (1988: 142) point out that even if particular values can be determined across societies, they 'can still show shifts of meaning'. Hoecklin (1994:3) claims that if 'globally operating companies want their philosophies, objectives, products and services to be [...] believed [...], they must attend to what these things mean to the people in each culture'. Schwartz and Bilski (1990) conducted investigations of the 36 values, Rokeach (1973) defined to comprehensively describe cultures. They found just seven of them to be relevant across the investigated societies. Schein (1985) recommends a general distinction between basic assumptions and norms. While both can represent basic values, they differ in terms of visibility. In Figure 2 the types of cultural phenomena considered in each of the conceptual models of Osgood (1951), Schein (1985), Schnyder (1988) and Hofstede et al. (2010, first ed. 1997) are contrasted against Schein's understanding of the dimension "visibility" (grey).

Figure 2: Cultural phenomena in different models contrasted according to their visibility

\begin{tabular}{|c|c|c|c|}
\hline OsGoOD (1951) & SCHEIN (1985) & SCHNYDER (1988) & HOFSTEDE (1997) \\
\hline \multirow{3}{*}{$\begin{array}{c}\text { descriptive } \\
\text { Percepta } \\
\text { (behaviour \& artefacts) }\end{array}$} & \multirow{3}{*}{$\begin{array}{l}\text { tangible level } \\
\text { of artefacts and } \\
\text { creations }\end{array}$} & tangible level & symbols \\
\hline & & \multirow{4}{*}{$\begin{array}{l}\text { (cognition; evaluation: } \\
\text { norms, patterns for } \\
\text { orientation, values) } \\
\text { intangible level } \\
\text { (interpretation: } \\
\text { potentials for the } \\
\text { transfer of meanings) }\end{array}$} & heroes \\
\hline & & & rituals \\
\hline (norms) & level of norms & & \\
\hline $\begin{array}{c}\text { Concepta } \\
\text { (perceptions, beliefs, } \\
\text { values, basic } \\
\text { assumptions) }\end{array}$ & $\begin{array}{l}\text { level of basic } \\
\text { assumptions }\end{array}$ & & values \\
\hline
\end{tabular}

visibility according to Schein (1985)

For the contrasting, these conceptual models were chosen because all four authors considered the dimension "visibility" in their discussion as well as having assigned values a high level of relevance. In contrast to Hofstede, all other approaches promote a more detailed level of differentiation on this level. In terms of visibility, which is highly relevant for the choice of research-methodologies, a limitation to "values" appears not detailed enough to determine cultural characteristics for artifact design.

With the term "Rituals", Hofstede et al. (2010) subsume all types of rituals and rites. This understanding is based on the functionalist model, which is attributed to Gluckman (1954), who defines rituals as significant, culture-specific resources for preventing and solving conflicts. Gluckman considers rites and traditions as rituals. The functionalist model represents just one position within a controversial discussion, which mainly focuses on the basic distinction between rituals and habits. In this discussion, rites often are not classified as rituals because proposed relevant characteristics are not met: Bell (1953) and Schröter (2004) understand rituals as mechanisms inherently to stabilize a society. Turner (1968: 30) defines 
rituals as 'mechanisms that periodically convert the obligatory into the desirable'. According to Alexander (1997: 139), a ritual 'is a performance, planned or improvised, that effects a transition from everyday life to an alternative context'. Wallace (1966) subdivides rituals into two distinct groups. Rituals that follow a certain routine according to the calendar, usually involve the whole society. All others are related to particular events, carried out on demand, and often, not the whole society is involved. According to Michaels (1999: 30, 34) rituals are always related to transformations as passages from dichotomies, for example, from impure to pure. Michaels claims that every ritual includes a formal decision and follows a formal procedure. What's more, rituals are publicly recognizable and are never carried out incidentally. For Bowie (2000: 153), rituals always have both a symbolic and a transcendental character. Fögen (1999: 156) emphasises that in contrast to habits, there is no option to conduct a particular ritual in a different way because else; it would be something different.

With the category "Heroes", Hofstede addresses persons to whom particular characteristics are assigned - characteristics that a society understands to be worth copying in order to improve social life. In the anthropological literature, the use of the term "heroes" is usually limited to the context of mythic heroes. Campbell (1949: 59) defines mythic heroes as figures that represent 'the benign, protecting power of destiny'. Lord (2003) explains that such a person undergoes a particular quest and is being transformed into the mythic hero after its end. In the sense of Hofstede's "Heroes", the term "archetypes" is more common. For Jung (1958: 573), archetypes are "no longer a personal but a purely supra-personal nature and are therefore common to all men'. One basic difference between Jung's understanding of archetypes and Hofstede's "Heroes" is that Jung does not limit archetypes to "light-figures" but also includes "shadowfigures" as stand-alone characters or as a light-figure's counterparts. The perception of heroes and "antiheroes" can differ between societies: A hero in one society actually can even be perceived as an antihero in another. Further on, Kølvraa (2012: 751) claims that a person becoming a public figure, 'becomes less of an individual and more of a symbol, his name referring no longer to the particularity of a life lived, but to the sacred symbolic centre of the community'. In this sense, a sharp distinction between heroes and symbols would at least lead to inconsistencies regarding their persistence over time.

With their definition of "Symbols", Hofstede et al. (2010: 8) subsume all types of symbols, i. e. "words, gestures, pictures, or objects'. Within a single socio-cultural context, meaning and significance of related phenomena are well known and shared. The examples of symbols provided by Hofstede et al. (2010: 8), which are all related to the current zeitgeist, might have led to the conclusion that 'New symbols are easily developed and old ones disappear'. According to Hofstede et al. (2010: 8), symbols generally have the lowest persistence amongst all other types of cultural phenomena.

The literature provides no unified definition on what exactly symbols are. One of the difficulties in finding a common understanding is related to the anthropologic distinction of symbols into "signum repraesentativum" and "signum significativum". A signum repraesentativum accentuates the general existence and the being, based on values and basic assumptions. In contrast, a signum significativum represents attributes/characteristics of life, for example ideas, perceptions, and achievements. In anthropological literature, the latter group is often not considered as symbols, but instead, because of their rather obvious character, as for research more or less insignificant signs. Thiel (1979: 552) distinguishes between symbols that represent an aspect of life, symbols in which the sheer existence/being shines through (transparency), and symbols, which are perceived as an inseparable unity (the same) with the related attributes/artefacts. Turner (1967:48) defines symbols as 'something that connects the unknown with the known'. According to Turner (1969a: 12), the meaning and significance of a particular symbol can exclusively be determined in and for the context of a selected socio-cultural context. Geertz (1957) and White (1959) emphasize that symbols with the same appearance can basically differ in their meanings across societies and contexts, and the same expression can be symbolized in different ways. Turner distinguishes between two types of symbols, i.e. dominant and ritual symbols. While dominant symbols represent basic assumptions and values, all other kinds of symbols are understood as ritual symbols. Signa repraesentativa are not considered in his classification. A reason for this can be found in Turner's specific research context: Turner investigated indigenous African societies, which were highly pragmatic in focusing on their daily life and survival (Turner, 1969b) instead of caring for profit, comfort and diversion. 
For Katz and Katz (1977: 486), the 'totality of symbols shared by the members of a culture can be understood to delineate that culture'. Symbols can take a variety of shapes and can be used in very different contexts, i.e. 'in spoken and written language, in art forms, in mundane daily work activities. They exist in both the sacred and the secular realms of culture'. In order to fully understand the meaning and relevance of a particular symbol within a socio-cultural context, Katz and Katz (1977:487) state that two characteristics ('potentials') need to be investigated, the 'inertial' and the 'adaptive' potential. While 'the meanings attached to the symbols generally tend to remain constant over time [...] some form of accommodation will be reached as different cultures come in contact'. Rafaeli and Worline (2000:72-73) claim that symbols are 'not simply by-products of organizations' but 'elements that structure members' active construction of sense, knowledge, and behaviour'. To which extent Hofstede's 'pictures' and 'objects' (2010: 8) also include architecture and art (in general) is unclear, but it can be assumed that these are part of the category "Symbols". In this context, Schein (2010: 23) urges a distinction between tangible and intangible artefacts.

\subsection{THE PERSISTENCE OF CULTURAL PHENOMENA}

Hofstede's Onion Model of Culture expresses that culture generally changes over time. This assumption is agreed across disciplines (Boyd \& Richerson, 1985; Beer, 2003; Hummel \& Zander, 2005). The historian Braudel (1992) categorizes the influence of time towards changes in societies according to three different kinds of "rhythms", which are the time of long periods, the time of medium-term changes, and the time of short periods. The time of long periods mainly describes geographical phenomena, which change so slowly that people are almost unable to recognize them within their rather short life span. Braudel understands such phenomena as the stabilizing elements amongst the other historical rhythms of change. He assigns the medium-term changes to the rise, development and downfall of societies and the time of short periods to sudden historical events. According to Braudel's theory, it is unlikely that cultural changes generally follow a certain, predictable pattern. Particularly when historical events are involved, spontaneous changes on all levels of human affairs can be expected to happen. Through closed lines, Hofstede et al. (2010) imply that the four cultural phenomenon types considered in the Onion Model of Culture could sharply be distinguished towards the expected frequency of cultural changes. Even though some kinds of cultural phenomena actually appear to have a shorter life span than others, the following two examples for exceptions from the context of Christian history and traditions challenge the claim for absoluteness:

1. While the inviolability of the matrimony, established in Christian societies as a basic value in 401 A.D., divorce became a legally and socially accepted practice across western societies after the sexual revolution in the 1960s. At a similar point of time, in 431 A.D., the council of Ephesos established the cross as the symbol to represent Christianity. The cross as symbol remained inherent for Christian societies.

2. Since 385 A.D., the pope is understood as the living representative of the Christian (later on, Catholic) Church. According to Hofstede's classification, the pope must be understood as a "Hero". Thus, related to example number 1 , also heroes can outlast basic values.

Soderberg and Holden (2002:112) express that culture generally needs to be understood 'as being made up of relations rather than a stable system of form and substance'. A change of relationships on any level of a society might also lead to cultural changes in the respective context. Thus, particularly for the usercentred, culture-sensitive design of artifacts, validity-related investigations are required, if already available data shall be reused, particularly in another project or even a different context.

\subsection{THE ORIGIN OF CULTURAL BIASING}

According to Hofstede et al. (2010: 9-14), "Values" are learned exclusively during childhood: Children adopt their perceptions of any kind of basic values from their parents and other people involved in their education: Hofstede (1999: 39) claims that 'after the age of 12 such values are firmly imprinted and hardly 
changeable' and that they inevitably pass them along to their own children. Hofstede further assumes that, in contrast to basic values, phenomena of all other types are constantly learned, modified, and substituted during a lifetime through practices.

The following discussion exclusively associates the cultural phenomenon type "Values" with "basic assumptions". Including norms would not make sense because any adjustments of norms (in the meaning of laws) need to be immediately adopted by the members of the related society. There are theories but no studies available that explicitly focus on the point of time when basic values are learned, internalized, and being applied to value-systems. Massey (1979) distinguishes between three periods in which the value-based view of the world is mainly developed: Up to the age of seven, information is simply absorbed within the "imprinting period" without further reflection. During the "modelling period", which starts around eight years of age, children copy the behaviour of others, although still not reflecting reasons. In the "socialization period", starting from 13 years of age, reflection takes place, largely influenced by peers. While Massey generally supports the concept of values imprinted during early childhood, he neither promotes the idea of a permanent imprinting nor does he agree with an unconscious and inevitable transfer across succeeding generations (also see Guss \& Miller, 2008). The assumed influence of childhood education on the organization of emotions and behaviour of adults is controversial (Grossmann et al., 1999). It is widely accepted that a mentally stable person constantly re-evaluates and reconstructs the own view of the world according to current requirements (Bowlby, 1995: 110-111). Lutzinger (2010) found that individual value-based concepts established during childhood could be easily manipulated, if the family situation did not provide clear enough structures.

\subsection{THE ONION METAPHOR}

With the onion metaphor, Hofstede et al. (2010: 7-8) illustrate the 'different levels of depth' in which the four considered types of cultural phenomena are imprinted within a person's mind. While the most superficial cultural phenomenon type "Symbols" is located in the far outer layer, the highest level of imprinting-depth is assigned to the core of the onion model ("Values"). With the decreasing level of depth from inside to outside, cultural phenomena types are more likely to be discarded.

There are several reasons why the onion metaphor and the onion peeling metaphor are problematic as they are assigned to Hofstede's Onion Model of Culture: In the biological sense, the core (sprout) of an onion has an outstanding functionality in relation to the surrounding layers, which are obliged to ensure its basic nutrition. The encapsulating layers, on the contrary, have an equal meaning for the core amongst each other. They all serve to provide water and basic nutrition. A transfer of nutrients exclusively happens mono-directional, from layers to core. First, the closest inner layer is consumed by the core and all others follow (in case of need) subsequently from inside to outside. In Hofstede's model, only three out of the four cultural phenomena types are represented as layers. The core represents the fourth considered phenomenon type, "Values". This exposure implies that the cultural phenomenon type "Values" is something basically different. In its position in the core, it serves as the reference point for all other types of cultural phenomena. For a consistent illustration of differences in imprinting-depth and an equitable consideration of the cultural phenomena types, all types of cultural phenomena would need to be represented by encapsulating layers. A distinct but common reference point would be required as the onion core.

In the original onion model, the dimension "persistence over time" is represented by the onion peeling metaphor: One after another layer is peeled from outside to inside, which symbolizes that the further outside a phenomenon is assigned, the earlier it will be discarded. Assumed that the chosen phenomenon types generally have such different life spans, there is a second characteristic of the peeling process which weakens the metaphor: In the process of peeling it is impossible to peel an inner layer without having previously peeled away all (related) layers further outside. This indicates that more persistent cultural phenomena can only change, if related less persistent phenomena changed beforehand. Taking the example of a symbol, which supports and plays an integral role in a particular ritual, the ritual could only change if the symbol had changed beforehand. While the ritual of the consecration as central part 
of the Christian holy mess changed several times through history (regarding the involved actors, the general context, the process itself, the used language, allowed participants, etc.), the cross as the representing symbol stayed the same. Assuming that norms have a different persistence than basic assumptions (in contrast to Hofstede's classification), a law, which (in this chosen case) is a norm, designed to enforce members of the society to respect a basic assumption would have to change, before the underlying basic assumption has been discarded or substituted. There is another weakness related to the role of the core in the peeling process: If the aim of peeling is to reach the core, the core is not part of the peeling process but its final product; peeling the core "away" would mean to throw it away, which would make the peeling process rather obsolete.

\subsection{TOWARDS A RECONSTRUCTION OF CULTURE}

Due to its simplicity, Hofstede's Onion Model of Culture appears well suitable for educational purposes in order to provide a very basic understanding on what the concept of culture is about. However, the investigation exposed some general difficulties for an adoption of the model as theoretical foundation for research, which are the outstanding characteristic assigned to basic values as referencing point for all other cultural phenomenon types, the assumption that a static sequence of "imprinting depth" (persistence) amongst the considered types of cultural phenomena exists, the idea that once established during childhood, basic values generally keep unchanged within an individual's view of the world, and finally, the assumption that basic values are exclusively learned during childhood (without reflection), while all other culture-specific perceptions are learned through practice. More specific limitations were found regarding the usefulness of the model as theoretical foundation in the context of DSR. In DSR, culture-related investigations are (economically) justified due to the necessity to develop culture-sensible artifacts in order to reach the highest possible level of acceptance amongst the future users. In order to achieve the necessary 'design knowledge' (Hevner et al., 2004: 23), details are required which cannot be deduced from the considered types of cultural phenomena. As for the adoption and reuse of data from earlier investigations, the statically modelled differences in persistence proved misleading. The specific choice of considered phenomena and the model's design suggest that collected data are forever persistent if related to basic values; this is not the case. As a conclusion, at least for its adoption in DSR, the model would require a higher level of detail and a generally different logic regarding the considered aspects of culture, their persistence, their focus, and their role for both the culture-holder as individual and the related society. In the following, the findings are transferred into a construct of culture, which considers cultural phenomena types and related entities on the one hand, and their dependencies and relationships on the other. On this basis, a culture model, namely, the "Onion Model of Culture 2.0" is being designed, which incorporates the requirements of DSR.

\subsection{ENTITIES, THE RELATION “RELEVANCE”, AND VARIABLES}

As entities in the following construction of culture, the diverse societies and their individual members are distinguished. In order to model culture in a way that artifacts can successfully be designed for selected user groups, their (expectable) perceptions and attitudes towards these artifacts need to be fully understood. Morris (1956: 198) made clear that people within a national society even differ in their understanding and evaluation of basic values according to their interests and obligations through their professions. Thus, in DSR, focusing culture-specific investigations on national culture is unlikely to lead to a user-specific design. Societies are further distinguished in core-societies and sub-societies. At least in a culturally homogenous country, a core society would be determined by national culture. However, in culturally heterogeneous countries, national culture can be limited to formal aspects like a national government and legislation. Müller (1996) found just two culturally (more or less) homogenous countries in the world, which were Germany and South Korea. Sub-societies usually respect and value the basic elements of the related core-society's culture but additionally, define own ethics, rules of conduct, etc. Amongst others, religion, political understanding, the same region, professions, associations, organizations, enterprises, families, age, ethnicity, and common interests can be reasons for the foundation of sub-societies. Each 
individual member of any society, namely the "culture-holder" has a particular understanding of the surrounding environment. This understanding is influenced by the rule- and mind-sets promoted through the diverse societies each culture-holder is member of.

From this point, the hitherto used term "imprinting depth" in the sense of "mental programming" is substituted through the relation "relevance". While "mental programming" implies the passive reception and inevitable adoption of preselected information, "relevance" promotes a relationship cultureholders have towards a particular cultural phenomenon, which is learned through a participatory process including the individual evaluation and reflection of information. The relation "relevance" thus, must be understood as an individually different evaluation criterion for cultural phenomenon types, which indicates, how likely cultural phenomena from one type are chosen over cultural phenomena from another. It must not be misunderstood as a measure for cultural phenomena on society level. Since culture herein has been defined as a majority criterion according to Oetting (1993), the relevance of a particular cultural phenomenon for a society would result from the evaluations the society's members have in common. In the following, the term "relevance" is defined on the basis of five general assumptions:

(1) In order to be accepted and respected, culture-holders are likely to attach a high relevance to societyspecific standards: These must be met in order to avoid social conflicts.

(2) General standards defined by core-societies are less likely to be directly influenced through an individual than standards from sub-societies in which the individual also is a member.

(3) For individuals, it is easier (technically) to discard the membership in a self-chosen sub-society than the membership in a core-society.

(4) Basing on (1), (2) and (3): If particular demands of a sub-society are considered to be inappropriate from the perspective of the core-society, an individual might try to influence such demands, leave the sub-society, or risk social conflicts.

(5) Some cultural phenomena types have a purely supportive (rituals) or representative (symbols) character without having further meaning in their own accord. Such cultural phenomena generally have less relevance and are more likely to being changed, ignored, or discarded than the cultural phenomena they are assigned to.

The variables "zeitgeist" and "the situation in life" are considered to influence the genesis of cultural phenomena and the perception of relevance members of a society have towards cultural phenomena. "Zeitgeist" and "the situation in life", reflect the second and third types of historical rhythms in Braudel's theory (1992). They are inherent in every social system. Both are influenced by but also constantly influence societies on different levels. Their origins are diverse but they cannot be considered as distinct cultural phenomena. Reasons for changes in zeitgeist or the current situation in life cannot reliably be predetermined; neither is it possible to precast the influences of such changes on an individual's mind-set or a society's culture. The "general view of the world" is another influence on the perception of the members of a society towards cultural phenomena, which requires consideration. It needs to be understood as an instrument that serves the individual as a basis for the evaluation of social environments. While it is not a distinct cultural phenomenon type, it is a result of an individual's situation of life, the current zeitgeist and the influences provided through the societies the individual is member of. As a collective phenomenon (perceptions the majority of members have in common), the "general view of the world" influences the direction a society takes for its further development.

\subsection{TYPES OF CULTURAL PHENOMENA}

The cultural phenomenon type "Values" from the original onion model turned out to be problematic due to several reasons. First, there generally is no consistent definition available for the term "values". In the literature, values vary between such abstract "things" like love, peace, and humility to concrete social norms. Second, the category "Values" - as Hofstede uses it - subsumes values, beliefs, and norms, which are cultural phenomena with different characteristics. Third, in terms of deriving the reasons for specific perceptions and attitudes, it is almost impossible to operationalize isolated basic values into a reliable and meaningful measuring scale. Last, the expression "(basic) values" has to be ethically challenged because of its implied indisputable character. With the alternative distinction between basic assumptions 
and norms, Schein (2010: 19) proposed a less focused approach, which is being adopted. In his sense, basic assumptions are taken for granted within a society and 'create the patterns of cognition, perceptions and feelings displayed by the members of the group' (Schein, 2010: 35). Norms, in contrast, are formalized (explicit) as well as non-formalized (implicit) rules defined within a society, which if not followed, lead to some kind of sanctions. Alternatively to the term "Norms" as introduced by Schein, the expression "social norms" is used in the following in order to emphasize that no limitation to written norms and standards is intended. In the original Onion Model of Culture, "beliefs" were included within the category "Values". For the new design, these are implemented as a distinct category: Beliefs result from the (often pragmatic) transfer of basic assumptions and social norms into an individual's view of the world but they neither are the one or the other. Given that people across two distinct societies assign the same level of relevance towards a particular basic assumption, the way in which they express it within their daily life might still differ. Schein's concept does not explicitly consider virtues, which, as the desirable aims of individual social development make a person become good and moral (e.g. Mauss, 1990: $157 \mathrm{ff}$.). For the construction of culture, virtues are assigned to beliefs; in the sense of 'values as the desirable' (Hofstede, 2001: 6).

In order to consider rites and traditions as "Rituals", the functionalist model is again being applied. Recognizing and understanding the rites and traditions of daily life can play a crucial role for a successful design of artifacts in terms of their usability and acceptance. Different to the setting in the original model and in order to explicitly consider both the rather traditional and the functionalist perspective, the original category "Rituals" is being divided into the two subtypes, formal rituals and non-formal rituals. Formal rituals are meant to emphasize the relevance of basic assumptions and particular events (e.g. a coronation), express religious faith, and support the communication with the divine. They are also carried out as vehicles to solve and avoid conflicts. Formal rituals correspond to what traditionally is meant to be a ritual in the context of culture anthropology. Non-formal rituals emphasize the common sense within a society, strengthen the community feeling, and remind us of historical events. What commonly is referred to as rites and traditions is included within this category. Non-formal rituals do not necessarily include transformations and the procedures can vary on demand.

The picture priory promoted through the original category "Heroes" revealed incomplete because the counterparts of heroes kept fully unconsidered. Furthermore, a distinction from the category "Symbols" was sheer impossible due to the symbolic meaning of heroes. Thus, the category "Heroes" is discarded as distinct type of cultural phenomena and transferred to the category "Symbols".

The original cultural phenomenon type "Symbols" is divided into sub-categories: First, a differentiation between symbols and artefacts is necessary. While symbols carry no particular meaning of their own accord but are related to and represent something different, artefacts actually are what they obviously represent, a language, a building, art, a role model, a piece of technology, an event, or a set of currently fashionable clothes. Schein (2010) stressed artefacts as a distinct type of cultural phenomena in order to consider differences regarding the dimension visibility. This dimension is relevant for the choice of research methods. While obvious phenomena can easily be monitored without influencing the research context, all others require more sophisticated methods for investigation. Following Turner (1969b), dominant symbols represent basic assumptions and values while all other types of symbols are classified as ritual symbols. Like the rituals they are related to, they might be inherently connected or exchangeable. This implies another level of distinction: In analogy to the prior classification of rituals, symbols, which are neither dominant symbols nor artefacts, shall be expressed as formal-ritual symbols and non-formal (ritual) symbols. In the context of anthropology, "signs" are understood as trivial symbols that have the sole purpose of representing specific branches, products or feelings. In investigations in the field, these are widely ignored because of their obvious character. Signs, however, still play a role for design decisions, as influences on contemporary and context-specific language or as indicators for a desired status. Signs are assigned to the category artefacts if carrying a meaning in their own accord. Else, if they constitute an integral part of a non-formal ritual, they are assigned to this category and referred to as nonformal symbols. 
The cultural phenomenon types behaviour and opinions were not considered as distinct phenomena within the original onion model, but require explicit consideration in the context of DSR. A detailed understanding of both can be crucial for culture-sensitive decisions on artifact-design in international settings and thus both categories are considered as distinct phenomena types. The category behavior includes the ways in which people transfer basic assumptions and social norms into activities of their own daily life. Behavior is influenced by the current zeitgeist and the situation in life within a society. Opinions and particularly "public opinions" reflect a society's contemporary culture. Opinions are expressed within art, self-presentation, perceptions, and attitudes (including behavior). Taking the enormous budgets as a measure, which firms and governments spend yearly for investigations into attitudes, the opinions of people are particularly relevant for political and economical decisions. Even though beliefs, basic assumptions, and social norms influence opinions through the culture-holders' views of the world, they are not necessarily fully reflected within opinions because of the (individuals and the society's) situations of life and the current zeitgeist. "Taste", as a non-tangible collective phenomenon (in terms of fashion), is included within the category opinions.

Figure 3 illustrates the found culture construct, which bases on the culture concept defined by Oetting. It includes supposed interrelations between the selected cultural phenomena types, considering the involved entities (along the horizontal axis according to the origin of cultural phenomena) and their estimated levels of influence (vertical axis, increasing from up to down). It is assumed that influence and relevance of the considered cultural phenomenon types increase in opposite directions. Explanations follow regarding the taken decisions for positioning of cultural phenomena on the different layers.

Figure 3: Construction of "Culture": Entities, variables, phenomena types and interrelations

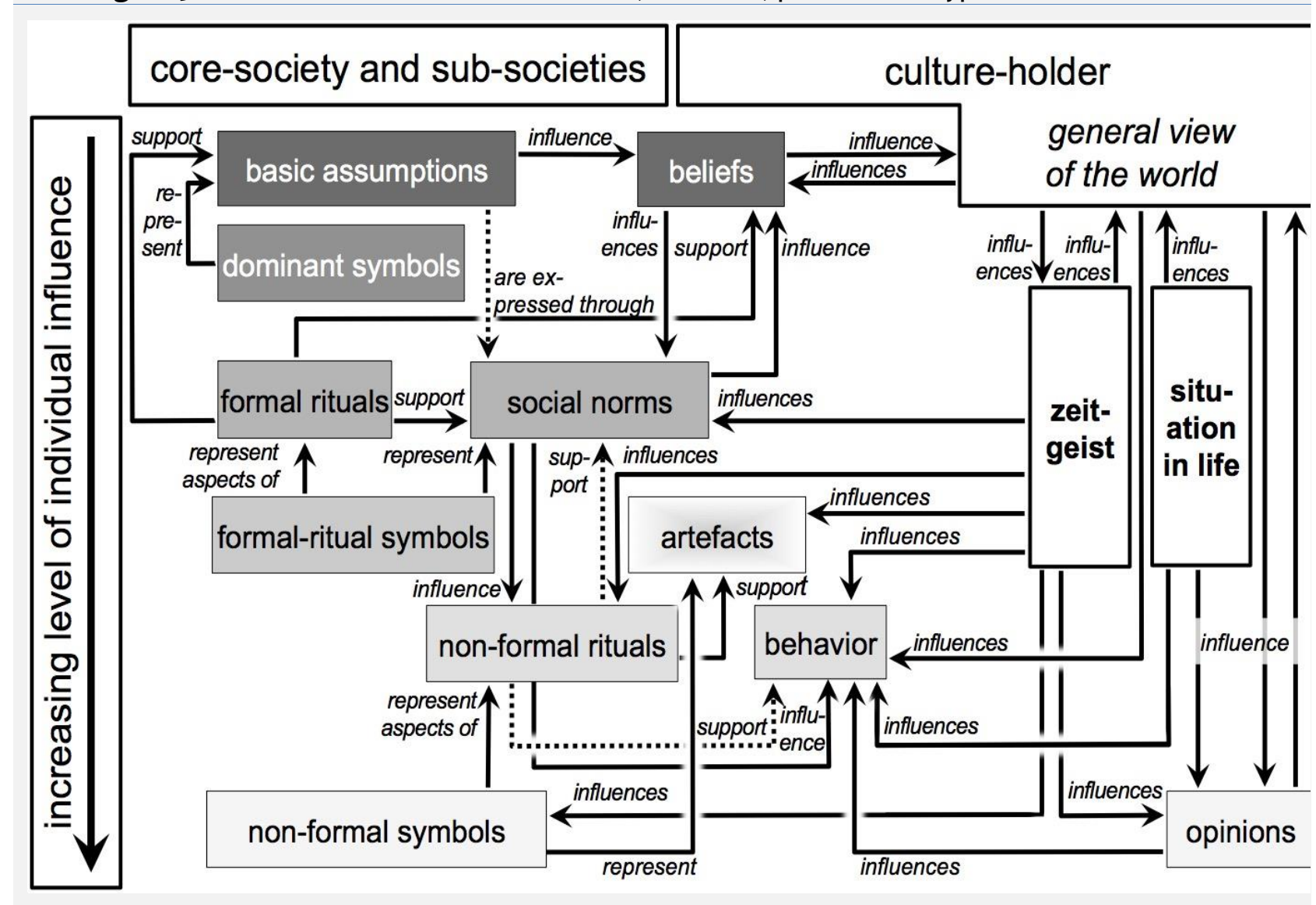

Layer 1: Basic assumptions are the most relevant phenomenon type for both society and individual culture-holders. The culture-holders transfer the taught basic assumptions into beliefs. To some extent, beliefs are something the whole core community has in common. Due to reflection processes, which directly and indirectly are influenced through several factors, beliefs might differ 
in detail, on the level of both sub-societies and individuals. Beliefs are the main drivers for the construction of any person's general view of the world.

Layer 2: Through their representative function, dominant symbols are directly and exclusively related to basic assumptions. Thus, for the time being, they can be considered on the same level as the basic assumptions they represent. However, according to the fifth general assumption, dominant symbols are assumed to be more likely modified or discarded and thus, allocated a level below. Individuals are unlikely to having enough influence to change dominant symbols.

Layer 3: Social norms mainly translate basic assumptions into rules of conduct for daily life on the level of core societies (symbolized through a broken line). When defined in the context of sub-societies, social norms might not be directly related to basic assumptions but rather be influenced through the beliefs, the members of a sub-society have in common. Individual culture-holders can directly (on sub-society level) or indirectly (e.g., through political elections) influence social norms. Social norms define which kind of behaviour generally is expected from the members of a society in order to secure and maintain the society. Social norms are influenced by the current zeitgeist, which they, in return, also influence themselves. After the relevance of a basic assumption has changed, it is likely that related social norms will be adopted accordingly. It cannot be assumed that social norms likewise influence their underlying basic assumptions. Formal rituals emphasize the relevance of basic assumptions and support the culture-holders' beliefs. With this characteristic, they (indirectly) also support social norms.

Layer 4: Formal-ritual symbols are designed to represent social norms and aspects of formal rituals. Formal-ritual symbols can vary in relevance between sub-societies. Artefacts are somewhat special amongst all cultural phenomena types since they are cultural phenomena in their own right. They are influenced and produced on all levels, from core society to individuals. They are not directly related to any other cultural phenomenon type. Artefacts can be tangible or non-tangible. First of all, they are influenced through the current zeitgeist. The positioning of artefacts on this level, as an assignment of relevance, is based on the supposition that basic assumptions and social norms are more relevant.

Layer 5: Behavior is what individuals actually do in the diverse situations according to their general view of the world. Behavior is indirectly influenced by, but does not necessarily fully reflect one's beliefs because social norms, the current zeitgeist, the situation in life, and also personal opinions are major influences. Since behavior is openly visible to others and may lead to consequences if it deviates too much from what the society is able or willing to accept, it is expected to be more relevant for the culture-holders than their opinions. Non-formal rituals mainly support artefacts. They are carried out on all society levels (e.g., in the contexts of youth or organizational culture). Non-formal rituals can support the maintenance of historical events and ancient traditions. They can be opening ceremonies for museums and be implemented in the context of music festivals or other festivities (which all, themselves, are artefacts). They can also manifest in rather particular contexts, be it in very specific modes for greetings or as parts of an agenda at business dinners. On sub-society level, non-formal rituals can also support social norms (symbolized through a broken line). Additionally, non-formal rituals can have a supportive function for behavior (symbolized through a broken line). They are directly influenced by the current zeitgeist and social norms.

Layer 6: Opinions and non-formal symbols are supposed to have the lowest relevance (in terms of the likeliness to being changed) for culture-holders amongst all considered cultural phenomenon types. Non-formal symbols are meant to represent aspects of non-formal rituals as well as artefacts (as directly related signs). They can be designed and used on all society levels. Opinions are mainly influenced by the culture-holders' general view of the world, the situation in life, and the current zeitgeist. Opinions are not necessarily in line with beliefs but directly influence behaviour. Opinions should not be underestimated: They can scale up in their absolute level of relevance if shared by a critical mass of culture-holders. In such cases, they can even influence social norms and basic assumptions.

\subsection{THE “ONION MODEL OF CULTURE 2.0”}


For the reconstruction of the conceptual culture model, the onion with its layers was again chosen as metaphor, even though the formerly applied onion peeling metaphor proved to provide insufficient applicability in the context of culture. As an alternative, the shape of an artichoke could have been a reasonable choice as suggested by Singleton and Reyna (1995: 628) because different to the onion, the artichoke is being peeled including the core and each of the layers is a subject of interest because carrying something valuable. However, in this type of model, the core would still have an outstanding role when applying the peeling metaphor: The core of the artichoke simply is its best part. As another argument to stick with the onion model, Goodman (1976: 68) claims that erasing a once established metaphor from the people's minds is sheer impossible. Cohen and Margalit (1970: 469) suggest 'see[ing] the death of a dead metaphor as a readjustment'. In this sense, the onion metaphor was adopted but readjusted according to its purpose and meaning. Figure 4 illustrates the Onion Model of Culture 2.0.

In this the Onion Model of Culture 2.0, the core of the onion represents the culture-holder as a distinct entity. It serves as the reference point in the system. This design ensures that the former accentuation of basic values as something outstanding is set aside and additionally, the biological role of the onion core is reflected. Each considered cultural phenomenon type arranged as onion layers around the core must be understood as a container structure, holding the respective cultural phenomena (of one type) with their characteristics specific for an individual's cultural identity. The closeness of cultural phenomenon types to the core represents the supposed relevance related cultural phenomena have for the culture-holder as a member of a society. The general concept of the onion model focuses on the individual and leans on the biological sequence in which the onion sprout consumes the onion layers for its development. Herein, "consuming" is understood as a means of manipulation, which is easier to manage towards something in reach than towards something out of reach.

Figure 4: The Onion model of culture 2.0

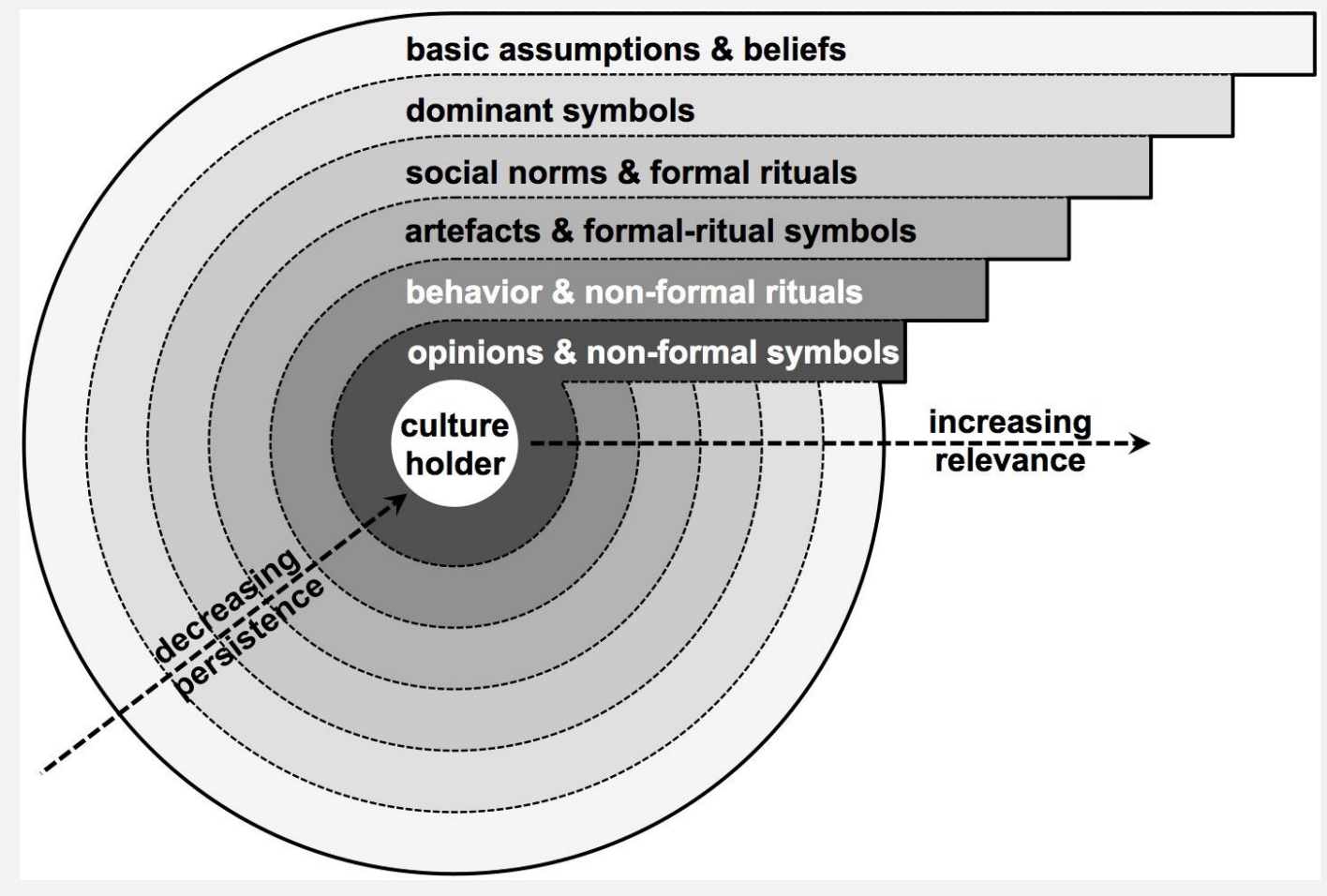

The metaphor "closeness to the core" symbolizes the level of influence a culture-holder can take regarding the design, establishment, redesign, substitution, and abolition of a certain type of cultural phenomena and so, the likeliness that their level of relevance changes. The metaphor indirectly refers to the dimension "persistence over time": As further a chosen (for investigation) cultural phenomenon is out of reach of the culture-holder in the centre, as more substantial (relevant) it is supposed to be for the community and consequently, for the individual (in terms of avoiding sanctions for shown non-conformity). It cannot be expected that all cultural phenomena of one type actually have the same relevance for 
the culture-holder at a certain point of time (and particularly not for all other culture-holders alike). The broken line separating the phenomenon types from each other shall symbolize that there is no fixed rule defining that one cultural phenomenon is more persistent than another (particularly not on the general level of phenomenon types). The applied sequence of the considered phenomena types represents a trend with the relation "more / less likely to being manipulated".

\subsection{CONCLUSION AND POLICY IMPLICATIONS}

In this contribution, the most frequently applied theoretical foundation for culture-specific investigations in economics has been reviewed and challenged on the example of DSR. The often applied concept of national culture as well as the reduction of culture to basic values, and a limited set of generic dimensions promote a picture of societies and people, which cannot reflect the complexity and measure of the people's perceptions and attitudes. Such a simplification results in a lack of understanding regarding highly relevant details; for product design as well as human resource management, international business, and other economically relevant contexts. Nowadays, we experience a mass-migration from regions with geographical, political and economical crises to more stable and secure environments in the western industrial countries. On the one hand, such a mass-migration constitutes a very difficult logistic and social challenge but on the other hand, it is a chance for the western industrial countries to cope with aging societies, far too low birth rates, and lacking manpower. However, without understanding the refugees' experiences, perceptions and attitudes, any strategy for integration might fail in the long term; as well as, e. g., the localization of products, which are meant to world-wide being distributed. A first step for a change in practice has been provided with the introduction of an conceptual culture model, which alternatively can serve as theoretical foundation for culture-related investigations.

The herein promoted "Onion Model of Culture 2.0" bases on a culture concept, which emphasizes that culture is not limited to basic values and national phenomena, and that it hardly can be reduced to a very limited number of generic dimensions. It suggests that individuals usually have the choice of membership in (sub-) societies and defines any society's culture as a number of perceptions and attitudes, the majority of its members has in common. For DSR and beyond, this concept is well supportive on both ethical and operational level. For the underlying construction of culture, which constitutes and the logic of the "Onion Model of Culture 2.0", the general dimensions "visibility", "persistence over time", "levels of societies", and "phenomenon types" were directly or indirectly considered. This reflects the current state of the art as promoted in cultural anthropology.

As another central step in the redesign of the model, the adopted onion metaphor, now, places the culture-holder - the individual - in its centre, which allows equally handling any type of cultural phenomena with the culture holder as reference point. For DSR and beyond, favouring a single type of cultural phenomena over others is risky in terms of cultivating blind spots towards actually relevant aspects and characteristics. The chosen design of the introduced conceptual model of culture generally encourages focusing on any cultural phenomenon type without preferences, and it promotes people as the origin of culture instead of defining them as helpless victims of an abstract power.

\section{REFERENCES}

Adler NJ, (2002). International dimensions of organizational behavior. $4^{\text {th }}$ Edition, Thompson South-Western, Cincinnati.

Ailon G, (2008). Mirror, mirror on the wall: Culture's consequences in a value test of its own design. Academy of Management Review, 33(4): 885-904.

Alexander BC, (1997). Ritual and current studies of ritual: Overview. In: SD Glazier (Ed.), Anthropology of religion: A Handbook, 139-160. Westport, CT: Praeger.

Ali RM., Tretiakov A, Crump B, (2009). Models of national culture in IS research. In: Proceedings of the 20th Australasian Conference on Information Systems, 246-256. Melbourne: Monash University. 
Baskerville R, (2008). What design science is not. European Journal of Information Systems, 17(3): 441443.

Beer B, (2003). Ethos; Ethnie; Kultur. In: B Beer, H Fischer (Eds.), Ethnologie. Einführung und Überblick, 53-72. Berlin: Reimer.

Bell CM, (1953). Ritual theory, ritual practice. New York: Oxford University Press. (herein used the 2009 published paperback edition)

Bowie F, (2000). The anthropology of religion: An introduction. Oxford: MPG Books Ltd.

Bowlby J, (1995). Bindung: Historische Wurzeln, theoretische Konzepte und klinische Relevanz. In G Spangler and P Zimmermann (Eds.), Die Bindungstheorie. Stuttgart: Klett-Cotta.

Boyd R, Richerson PJ, (1985). Culture and the evolutionary process. Chicago, USA: University of Chicago Press.

Braudel F, (1992). Schriften zur Geschichte I: Gesellschaften und Zeitstrukturen. Stuttgart: Klett Cotta.

Bruk-Lee V, Khoury HA, Nixon AE, Goh A, Spector PE, (2009). Replicating and extending past personality/job satisfaction meta-analyses. Human Performance, 22(2): 156-189.

Campbell J, (1949). The hero with a thousand faces, $3^{\text {rd }}$ Edition. Novato, California: New World Library.

Cohen J, Margalit A, (1970). The role of inductive reasoning in the interpretation of metaphor. Synthese, 21(3/4): 469-487.

Church TA, Katigbak MS, (1988). The emic strategy in the identification and assessment of personality dimensions in a non-western culture. Journal of Cross-Cultural Psychology, 19(2): 140-163.

Derr CB and Laurent A (1989). The internal and external career: A theoretical and cross-cultural perspective. In: MB Arthur, DT Hall, BS Lawrence (Eds.), Handbook of Career Theory, 454-471, Cambridge: University Press.

Douglas I, Liu Z, (2011). Global usability. London: Springer.

Drechsler A, (2013). Design science as design of social systems - Implications for information systems research. Journal of Information Technology, Theory and Application, 14(4): 5-26.

Ehn BE, Löfgren O, (2009). Ethnography in the marketplace. Culture Unbound, 1(1): 31-49.

Fang T, (2011). Yin Yang: A new perspective on culture. Management and Organization Review, 8(1): 2550.

Fögen MT, (1999). Ritual und Rechtsfindung. In: C Caduff, J Pfaff-Czarnecka (Eds.), Rituale heute: Theorien - Kontroversen - Entwürfe: 149-164, Berlin: Reimer.

Frank U, Schauer C, Wigand R, (2008). Different paths of development of two information systems communities: A comparative study based on peer interviews. Communications of the Association for Information Systems, 22(1): 391-412.

Gagliardi P, (1986). The creation and change of organizational cultures: A conceptual framework. Organization Studies, 7(2): 117-134.

Geertz C, (1957). Ethos, world-view and the analysis of sacred symbols. The Antioch Review, 17(4): 421437.

Gelfand MJ, Erez ME, Aycan Z, (2007). Cross-cultural organizational behavior. Annual Review of Psychology, 2007/58: 479-514.

Gelfand MJ, Nishii LH, Raver JL, (2007). On the nature and importance of cultural tightness-looseness. Journal of Applied Psychology, 91(6): 1225-1244.

Gluckman M, (1954). Rituals of rebellion in South-East Africa. Manchester: Manchester University Press.

Goeltz DR, (2014). Globalization and hypercompetition - Drivers, linkages, and industry differences. Journal of International Business and Cultural Studies, June 2014/8. http://www.aabri.com/manuscripts/141856.pdf. Accessed 12 October 2014.

Goodman N, (1976). Languages of art: An approach to a theory of symbols, $2^{\text {nd }}$ Edition. Indianapolis: Hackett Publishing.

Gregor S, Hevner AR, (2013). Positioning and presenting design science research for maximum impact. MIS Quarterly 37(2): 337-355.

Grossmann KE, Grossmann K, Zimmermann P, Cassidy J, (1999). A wider view of attachment and exploration: Stability and change during the years of immaturity. In: PR Shaver (Ed.), Handbook of attachment: Theory, research, and clinical applications, 760-78, New York: Guilford Press.

Guss E, Miller MC, (2008). Ethics and generational differences: Interplay between values and ethical business decisions. White Paper: http://www.shrm.org. Accessed 12. October 2014. 
Haire M, Ghiselli EE, Porter LW, (1966). Managerial thinking: An international study. New York: Wiley.

Hall ET, Hall MR, (1990). Understanding cultural differences. Yarmouth: Intercultural Press.

Hoecklin L, (1994). Managing cultural differences: Strategies for competitive advantage. USA: AddisonWesley Publishing Co. Inc.

Hevner AR, March ST, Park J, Ram S, (2004). Design science in information systems research. MIS Quarterly, 28(1): 75-105.

Hofstede G, (1980, 2001). Culture's consequences - international differences in work related values. London: Newbury Park (herein used the $2^{\text {nd }}$ edition from 2001, Thousand Oaks, CA: Sage).

Hofstede $\mathrm{G}$, Bond $\mathrm{MH}$, (1988). The confucius connection: from cultural roots to economic growth. Organizational Dynamics, 16: 4-21.

Hofstede G, Neuijen B, Ohayav DD, Sanders G, (1990). Measuring organizational cultures: A Qualitative and quantitative study across twenty cases. Administrative Science Quarterly, 35(2): 286-316.

Hofstede G, (1999). Problems remain, but theories will change: The universal and the specific in 21st-century global management. Organizational Dynamics, 28(1): 34-44.

Hofstede G, Hofstede GJ, Minkov M, (first ed. 1980, herein used 2010). Cultures and organizations: Software of the mind, $3^{\text {rd }}$ Edition. USA: McGraw-Hill Publishers.

House RJ, Hanges PJ, Javidan M, Dorfman PW, Gupta V, (2004). Culture, leadership, and organizations: The Globe Study of 62 societies. London: Thousand Oaks, Sage.

Hummel T, Zander E, (2005). Interkulturelles Management. In: T HUMMEL (Ed.), Schriften zum Interkulturellen Management, Band 10. Munich: Reiner Hampp Verlag.

Inglehart R, Wetzel C, (2010). Changing mass priorities: The link between modernization and democracy. Perspectives on Politics, 8(2): 551-567.

Jones ML, (2007). Hofstede - Culturally questionable? In: A Gupta, (Ed.), Proceedings of the 2007 Oxford Business \& Economics Conference, Oxford: Oxford University, http://www.gcbe.us/2007_OBEC/data/confcd.htm. Accessed 12 October 2014.

Jung CG (1958). The collected works of C. G. Jung. NY: Pantheon, Bullington Series 11.

Katz P, Katz FE, (1977). Symbols as charters in culture change: The Jewish case. Anthropos, 72(3-4): 486497.

Karahanna E, Evaristo JR, Srite M, (2006). Levels of culture and individual behaviour: An integrative perspective. Advanced Topics in Global Information Management, 5(1): 30-50.

Kirkman BL, Lowe KB, Gibson CB, (2006). A quarter century of culture's consequences: a review of empirical research incorporating Hofstede's cultural values framework. Journal of International Business Studies, 37(3): 285-320.

Kogut B, Singh H (1988). The effect of national culture on the choice of entry mode. Journal of International Business Studies, 19(3): 411-432.

Kluckhohn FR, (1953). Universal categories of culture. In: AL Kroeber, (Ed.), Anthropology today, 507-523, Chicago: University of Chicago Press.

Koester J, Olebe M, (1988). The behavioural assessment scale for intercultural communication effectiveness. International Journal of Intercultural Relations, 12(3): 233-246.

Kølvraa C, (2012). The father on display: The house of Jean Monnet and the construction of European identity. Culture Unbound, 4/2012: 747-765.

Köppel P, (2002). Kulturerfassungsansätze und ihre Integration in interkulturelle Trainings. Trier Beiträge zur gegenwartsbezogenen Ethnologie. Trier: Fokus Kultur.

Kuhn MH, McPartland R, (1954). An empirical investigation of self-attitudes. American Sociological Review, 19(1): 68-76.

Lai VS, Wong BK, (2003). The moderating effect of local environment on a foreign affiliate's global IS strategy-effectiveness relationship. IEEE Transactions On Engineering Management, 50(3): 352-361.

Leach-López MA, Jack EP, (2014). Hofstede's values - LOC: job satisfaction effect in the USA, Mexico, Korea, and Hong Kong. Journal of International Business Management, 8/2014, http://www.aabri.com/manuscripts/121237.pdf. Accessed 12 October 2014.

Leidner D, Kayworth T, (2006). A review of culture in information systems research: Toward a theory of information technology culture conflict. MISQ, 30(2): 357-399. 
Leung K, Ang S, (2009). Culture, organizations, and institutions: an integrative review. In: RS Bhagat and RM Steers, (Eds.), Cambridge Handbook of Culture, Organizations, and Work, 23-45, Cambridge: Cambridge University Press.

Lord R, (2003, reprint, orig. 1956). The hero: A study in tradition, myth, and drama. New York: Dover Publications Inc.

Lutzinger S, (2010). Die Sicht der Anderen. Cologne: Wolters Kluwer Deutschland GmbH.

Massey M, (1979). The people puzzle. Michigan: University of Michigan.

Mauss M, (1990). Die Gabe: Form und Funktion des Austauschs in archaischen Gesellschaften. Frankfurt, London: Suhrkamp.

McSweeney B, (2002). Hofstede's model of national cultural differences and their consequences: A triumph of faith - a failure of analysis. Human Relations, 55(1): 89-118.

Michaels A, (1999). „Le rituel pour le rituel“ oder wie sinnlos sind Rituale? In: C Caduff and J Pfaff-Czarnecka (Eds.), Rituale heute: Theorien - Kontroversen - Entwürfe, 23-48, Berlin: Reimer.

Morris C, (1956). Varieties of human value. Chicago: Chicago University Press.

Müller H-P, (1996). Kulturelle Gliederung der Entwicklungsländer. In: MÜLLER H-P (Ed.), Weltsystem und kulturelles Erbe, 81-137, Raimer Verlag, Berlin.

Ng SI, Lee JA, Soutar GN, (2007). Are Hofstede's and Schwartz's value frameworks congruent? International Marketing Review, 24(2): 164-180.

Norman D, (1988). The design of everyday things. New York: Doubleday.

Nunamaker Jr JF, Briggs RO, (2012). Toward a broader vision for information systems. ACM Transitions of Management Information Systems, 2(4): 20:1-20:12.

Oeser E, (1990). Evolution und Selbstkonstruktion des Rechts: Rechtsphilosophie als Entwicklungstheorie der praktischen Vernunft. Wien, Cologne: Böhlau Verlag.

Oetting ER, (1993). Orthogonal cultural identification: Theoretical links between cultural identification and substance use. In: MR de la Rosa, J-L R Andrados, (Eds.), Drug Abuse Among Minority Youth: Methodological Issues and Recent Research Advances, 32-56, Rockville, MD: National Inst. on Drug Abuse (DHHS/PHS).

Osgood C, (1951). Culture: Its empirical and non-empirical character. Southwestern Journal of Anthropology, 7(2): 202-214.

Pelto P, (1968). The difference between "tight" and "loose" societies. Transaction, 5(1): 37-40.

Pless NM, Maak T (2004). Building an inclusive diversity culture: Principles, processes and practice. Journal of Business Ethics, 54(2): 129-147.

Rafaeli A, Worline M, (2000). Symbols in organizational culture. In: NM Ashkanasi, CPM Wilderom, MF Peterson, (Eds.), Handbook of Organizational Culture and Climate, 71-84, Thousand Oaks, CA Sage.

Rokeach M, (1973). The nature of human values. New York: Free Press.

Ruch FL, Zimbardo PG, (1974). Lehrbuch der Psychologie: eine Einführung für Studenten der Psychologie, Medizin und Pädagogik. Heidelberg, New York: Springer.

Schein EH, (1985, 2010). Organizational culture and leadership. San Francisco: Sossey-Bass. (herein, the $4^{\text {th }}$ Edition from 2010 was used)

Schnyder AB, (1988). Unternehmenskultur. Die Entwicklung eines Unternehmungskultur- Modells unter Berücksichtigung ethnologischer Erkenntnisse und deren Anwendung auf die InnovationsThematik. Europäische Hochschulschriften, Serie V, Band 987. Bern, Frankfurt: Verlag Peter Lang.

Scholz C, (2000). Personalmanagement. $5^{\text {th }}$ Edition, Munich: Vahlen.

Schröter S, (2004). Rituals of rebellion. A theory reconsidered. In: J Kreinath, C Hartung, A Deschner, (Eds.), The Dynamics of changing rituals: The Transformation of Religious Rituals within Their Social and Cultural Context, Toronto Studies in Religion 29, 41-58, New York: Peter Lang.

Schwartz SH, Bilsky W, (1990). Toward a theory of the universal content and structure of values: Extension and cross-cultural replications. Journal of Personality and Social Psychology, 58(5): 878-891.

Schwartz SH, (1994). Beyond individualism/collectivism. New cultural dimensions of values. In: U Kim, HC Triandis, C Kagitcibasi, S Choi, G Yoon, (Eds.), Individualism and collectivism, theory, method and applications, 85-119, Thousand Oaks: Sage.

Schwartz SH, (1999). A theory of cultural values and some implications for work. Applied Psychology: An International Review, 48(1): 23-47. 
Singleton M, Reyna SP, (1995). Science - artichoke or onion? The Journal of the Royal Anthropological Institute, 1(3): 628-631.

Smith PB, (2006). When elephants fight, the grass gets trampled: the GLOBE and Hofstede projects. Journal of International Business Studies, 37(6): 915-921.

Soderberg A-M, Holden N, (2002). Rethinking cross-cultural management in a globalizing business word. International Journal of Cross-Cultural Management, 23(1): 101-121.

Straub DW, Loch K, Evaristo R, Karahanna E, Strite M, (2002). Need for a theory-based individual (versus universal) conceptualization and measurement of culture. In: F Tan, (Ed.), Advanced Topics in Global Information Management, Vol. 2, 39-48, Hershey: Idea Group.

Tarras V, Steel P, (2009). Beyond Hofstede: Challenging the ten commandments of cross-cultural research. In C Nakata, (Ed.), Beyond Hofstede: Culture frameworks for global marketing and management, 40-60, New York: Palgrave Macmillan.

Tarras V, Rowney J, Steel PDG, (2009). Half a century of measuring culture: Review of approaches, challenges, and limitations based on the analysis of 121 instruments for quantifying culture. Journal of International Management, 15(4): 357-373.

Tajfel H, Turner JC, (1986). The social identity theory of intergroup behaviour. In: S Worchel and WG Austin (Eds.), Psychology of intergroup relations, 7-24, Chicago: Nelson-Hall.

Thiel M, (1979). Symbole. In: M Lurker, Wörterbuch der Symbolik. Stuttgart: Kröner. http://www.symbolforschung.org/Symbole.html. Accessed 01 November 2014.

Trompenaars F, Hampden-Turner C, (1997). Riding the waves of culture: Understanding cultural diversity in business. Nicholas Brealey Publishing, London.

Tsui AS, Nifadkar SS, Olu AY, (2007). Cross-national, cross-cultural organizational behaviour research: Advances, gaps, and recommendations. Journal of Management, 33(3): 426-478.

Turner V, (1967). The forest of symbols. USA: Cornell University Press.

Turner V, (1968). The drums of affliction: A study of religious processes among the Ndembu of Zambia. Oxford: Clarendon Publishing.

Turner V, (1969a). Forms of symbolic action: Introduction. In: RE Spencer, (Ed.), Proceedings of the 1969 annual spring meeting of the American ethnological society, 3-25, Seattle: American Ethnological Society.

Turner V, (1969b). The ritual process - Structure and anti-structure. New Brunswick: Transaction Publishers. (herein used the $2^{\text {nd }}$ edition from 2009).

Wallace AF, (1966). Religion: An anthropological view. New York: Random House.

Westwood RG, Everett JE, (1987). Culture's consequences: A methodology for comparative management studies in South-East Asia? Asia Pacific Journal of Management, 4(3): 187-202.

White LA, (1959). The science of culture: A study of man and civilization. New York: Grove Press. 